\title{
The clinicopathological and prognostic role of thrombocytosis in patients with cancer: A meta-analysis
}

\author{
XIAOJING ZHANG ${ }^{1}$, ZUNFU LV ${ }^{2}$, HUA YU ${ }^{1}$ and JIANQING ZHU \\ ${ }^{1}$ Department of Gynecological Oncology, Zhejiang Cancer Hospital, Hangzhou, Zhejiang 310022; \\ ${ }^{2}$ Department of Agriculture and Food Science, Zhejiang Agriculture and Forest University, Lin'an, Zhejiang 311300, P.R. China
}

Received August 21, 2015; Accepted January 26, 2017

DOI: $10.3892 / \mathrm{ol} .2017 .6054$

\begin{abstract}
Previous studies have linked the presence of thrombocytosis with the progression and development of cancer; however, this trend requires further investigation. The present study aimed to derive an estimation of the degree of association between thrombocytosis and the 5 -year overall survival rate of patients with cancer, as well as common clinicopathological features, by performing a meta-analysis of $20(n=12,778)$ published studies. The PubMed and Embase databases were searched systematically for all relevant articles published in English. Odds ratios (ORs) with 95\% confidence intervals (CI) were calculated using a fixed effects or random effects model to evaluate the degree of the observed associations. The results suggested that thrombocytosis (platelet count, $>400 \times 10^{9} / 1$ ) correlated with a decreased 5-year overall survival rate $(\mathrm{OR}=2.70$, 95\% $\mathrm{CI}=2.03-3.61)$ and an advanced tumor-node-metastasis stage (III + IV; OR=2.14, 95\% CI=1.58-2.90). Furthermore, these associations remained robust following stratification of the data by cancer type and ethnicity. In addition, thrombocytosis (platelet count, $>300 \times 10^{9} / 1$ ) correlated with a decreased 5-year overall survival rate in patients with colorectal cancer $(\mathrm{OR}=3.49,95 \% \mathrm{CI}=1.44-8.46)$. Although certain biases were not able to be eliminated, the present meta-analysis suggested that thrombocytosis is a valuable indicator for the evaluation of pathological diagnosis and prognosis for patients with cancer. Further studies are required to investigate the effect of thrombocytosis on the prognosis of patients with cancer.
\end{abstract}

Correspondence to: Dr Jianqing Zhu, Department of Gynecological Oncology, Zhejiang Cancer Hospital, 38 Guangji Road, Hangzhou, Zhejiang 310022, P.R. China

E-mail: jianqingzhuzi@126.com

Abbreviations: TNM, tumor node metastasis; OR, odds ratio; CI, confidence interval

Key words: thrombocytosis, cancer, prognosis, meta-analysis

\section{Introduction}

Despite improvements in early diagnosis, radical surgery and various novel treatments, the prognosis for patients with cancer remains poor (1). Esophageal cancer patients without detectable metastasis in the clinic at the time of diagnosis may still succumb to cancer recurrence following surgery (2). This suggests that certain metastasis of cancer may not be detected using conventional biochemistry testing, imaging or histopathological methods (2). Therefore, a novel biological marker that may enhance the ability to accurately predict patient treatment outcomes is required. In previous years, a number of studies have investigated potential prognostic factors in patients with cancer. Previous studies have demonstrated that certain preoperative alterations in hematological parameters may be associated with patient outcomes for several forms of solid tumors (3). In addition, it has been suggested that circulating platelet (PLT)-tumor cell aggregates may promote cancer metastasis (4).

Previous studies have investigated the association between thrombocytosis and tumor growth and development in various forms of malignancy (5-7); however, this trend requires further investigation. Yu et al (8) demonstrated, using a meta-analysis, that thrombocytosis (PLT count $>400 \times 10^{9} / 1$ ) may be associated with a poorer prognosis for patients with a gynecological malignancy. Therefore, the present meta-analysis was performed in order to assess the association between thrombocytosis, 5-year overall survival and tumor clinicopathological features in various types of cancer, excluding gynecological malignancies.

\section{Materials and methods}

Identification and eligibility of relevant studies. The PubMed (https://www.ncbi.nlm.nih.gov/pubmed) and Embase (https://www.elsevier.com/solutions/embase-biomedical-research) databases were searched with the following terms: 'Carcinoma' or 'cancer'; 'platelet count' or 'thrombocytosis'; 'prognosis' or 'survival' (the final search was performed on April 3rd, 2015). The associated reference articles were subsequently searched to identify any other relevant publications. Reference lists of all retrieved articles were also manually examined. If $>1$ article had been published using the same patient population, only the most recent or 
complete study was selected. Studies included in the present meta-analysis were required to meet the following inclusion criteria: Study was written in the English language; the study defined thrombocytosis as PLT counts $>300 \times 10^{9}$ platelets $/ 1$ in patients with colorectal cancer and PLT counts $>400 \times 10^{9}$ platelets/l for patients with other types of cancer; the study examined the association between thrombocytosis and the survival of patients with cancer and tumor clinicopathological features, including tumor differentiation, lymph node metastasis, and tumor node metastasis (TNM) stage which was measured in accordance with American Joint Commission for Cancer Staging (9).

The study exclusion criteria were as follows: The appropriate data was not able to be extracted from the published results; the study lacked information on clinicopathological features or survival; the study performed an evaluation of the association between thrombocytosis and forms of gynecological cancer.

Data extraction. Information was independently extracted from all eligible publications, according to the inclusion criteria. The primary aim was to assess the prognostic value of thrombocytosis, particularly regarding 5-year overall survival, in patients with cancer. The secondary aim was to evaluate the association between thrombocytosis and patient clinicopathological features. The following data were sought from each publication: The first author's last name, year and country of the study, cancer type, number of patients with and without thrombocytosis, 5-year overall survival and clinicopathological features, including tumor differentiation, lymph node metastasis, TNM stage and tumor location.

Statistical analysis. The degree of the association between thrombocytosis and the 5-year overall survival rate and tumor clinicopathological features in various types of cancer was evaluated by odds ratios (OR) with $95 \%$ confidence intervals (CI). The statistical significance of the pooled OR was determined using the z-test. The $\chi^{2}$ test-based Cochran's Q-statistic was calculated to evaluate the heterogeneity between studies. If the between-study heterogeneity was significant, then the pooled ORs were analyzed using the random effects model (the DerSimonian and Laird method) (10); otherwise, the fixed effects model was selected (the Mantel-Haenszel method) (11). Subgroup analyses, in which studies were subdivided by cancer type and ethnicity, were adopted to minimize the influence of heterogeneity on the results. Funnel plots and Egger's linear regression test were used to evaluate potential publication bias. All analyses were performed using Stata software version 11.0 (StataCorp LP, College Station, TX, USA), and all tests were two sided. $\mathrm{P}<0.05$ was considered to indicate a statistically significant difference.

\section{Results}

Identification of eligible studies. A total of 20 studies (7,12-30) that met the inclusion criteria were retrieved for analysis in the present study. The selection process of the included studies is presented in Fig. 1. The number of patients in each study ranged between 100 and 3,139 and the total number of patients included in the present study was 12,778 , of whom 1,739 exhibited thrombocytosis at the time of initial diagnosis. The characteristics of each study are summarized in Table I, and 19/20 of the included studies provided data on the association between 5-year overall survival and thrombocytosis. The types of cancer examined by the 20 studies included in the meta-analysis were as follows: 4 gastric, 4 lung, 7 renal and 5 colorectal cancer.

Correlation between thrombocytosis and 5-year overall survival. The present meta-analysis indicated that thrombocytosis (defined as a PLT count of $>400 \times 10^{9}$ platelets $/$ l) was associated with a 2.70 -fold increase in mortality, as compared with patients with normal PLT counts, when the 5-year overall survival rate was extracted from 15 eligible studies $(\mathrm{OR}=2.70 ; 95 \% \mathrm{CI}=2.03-3.61)$. The random effects model was utilized for analysis due to the heterogeneity of the studies examined $\left(I^{2}=69.6 \%\right)$. Upon stratification by cancer type, the pooled ORs for gastrointestinal, lung and renal cancer were 1.77 (95\% CI=1.36-2.29), 3.21 (95\% CI=1.75-5.92) and 3.11 (95\% CI=2.03-4.77), respectively (Fig. 2). In addition, thrombocytosis (defined as a PLT count of $>300 \times 10^{9}$ platelets $/ 1$ ) was associated with reduced 5 -year survival rate $(\mathrm{OR}=3.49$, $95 \% \mathrm{CI}=1.44-8.46$ ) in patients with colorectal cancer. When subdivided by ethnicity, the pooled ORs for Asian, African and European populations were 3.06 (95\% CI=1.76-5.34), 1.71 (95\% CI=1.17-2.49) and $2.72(95 \% \mathrm{CI}=1.91-3.90)$, respectively (Table II).

Correlation between thrombocytosis and tumor clinicopathological features. Analysis of the correlation between thrombocytosis (PLT $>400 \times 10^{9} / 1$ ) and the pooled clinicopathological feature data revealed that thrombocytosis was more frequently detected in patients with an advanced TNM stage $\left(\mathrm{OR}=2.14,95 \% \mathrm{CI}=1.58-2.90 ; I^{2}=54.1 \%\right)$. By contrast, no statistically significant association was identified between thrombocytosis and tumor differentiation $(\mathrm{P}=0.31)$, lymph node metastasis $(\mathrm{P}=0.097)$ or tumor location $(\mathrm{P}=0.24)$. Subgroup analyses were subsequently performed according to cancer type, and the pooled ORs for gastrointestinal, lung and renal cancer were 1.96 (95\% CI=1.21-3.18), 1.96 (95\% CI=1.23-3.12) and 3.16 (95\% CI=3.16-8.32), respectively (Table II). In the subgroup analysis according to ethnicity, as there was no study investigating the association between thrombocytosis and advanced TNM stage in African patients, the pooled ORs for Asians and Europeans were 2.64 (95\% CI=1.42-4.90) and 1.89 (95\% CI=1.38-2.59), respectively (Fig. 3).

Heterogeneity and sensitivity analyses. The present meta-analysis detected significant between-study heterogeneity (5-year overall survival, $\mathrm{P}_{\text {heterogeneity }}<0.001 ; I^{2}=69.6 \%$; TNM stage, $\mathrm{P}_{\text {heterogeneity }}=0.03 ; I^{2}=54.1 \%$ ). However, stratification based on the type of cancer reduced the heterogeneity observed in the gastrointestinal cancer subgroups (5-year overall survival, $\mathrm{P}_{\text {het- }}$ erogeneity $=0.57, I^{2}=0.0 \%$; TNM stage, $\mathrm{P}_{\text {heterogeneity }}=0.17, I^{2}=44.3 \%$ ). In addition, there was no heterogeneity for studies investigating the association between thrombocytosis and 5-year overall survival in Africans $\left(\mathrm{I}^{2}=0 \%\right)$, and TNM stage in Europeans $\left(\mathrm{I}^{2}=30.6 \%\right)$. The source of heterogeneity was assessed for comparison of patient 5-year overall survival according to ethnicity, cancer type and sample size (>200 patients in 
Table I. Characteristics of the eligible studies.

\begin{tabular}{|c|c|c|c|c|c|c|}
\hline First author & Year & Country & Cancer type & $\begin{array}{c}\text { Threshold } \\
\text { level for } \\
\text { thrombosis, } \mathrm{x} 10^{9} / 1\end{array}$ & $\begin{array}{l}\text { Total no. } \\
\text { of patients }\end{array}$ & $\begin{array}{c}\text { No. of patients } \\
\text { with } \\
\text { thrombocytosis }\end{array}$ \\
\hline Li (7) & 2014 & China & Gastric & 400 & 1,596 & 120 \\
\hline $\mathrm{Hu}(12)$ & 2014 & China & Gastric & 400 & 313 & 71 \\
\hline Hwang (13) & 2012 & Egypt & Gastric & 400 & 1,593 & 102 \\
\hline Wang (14) & 2012 & China & Gastric & 400 & 100 & 21 \\
\hline $\operatorname{Kim}(15)$ & 2014 & Egypt & Lung & 400 & 199 & 15 \\
\hline Maráz (16) & 2013 & Hungary & Lung & 400 & 398 & 86 \\
\hline Tomita (17) & 2007 & Japan & Lung & 400 & 244 & 14 \\
\hline Pedersen (18) & 1996 & Denmark & Lung & 400 & 1,115 & 357 \\
\hline Venkatramani (19) & 2015 & India & Renal & 400 & 320 & 33 \\
\hline Brookman-May (20) & 2013 & Germany & Renal & 400 & 3,139 & 277 \\
\hline Wosnitzer (21) & 2010 & USA & Renal & 400 & 958 & 91 \\
\hline Suppiah (22) & 2006 & USA & Renal & 400 & 700 & 175 \\
\hline Göğüus (23) & 2004 & Turkey & Renal & 400 & 151 & 21 \\
\hline Inoue (24) & 2004 & Japan & Renal & 400 & 196 & 16 \\
\hline Symbas (25) & 2000 & USA & Renal & 400 & 259 & 147 \\
\hline $\operatorname{Kim}(26)$ & 2015 & Egypt & Colorectal & 370 & 314 & 69 \\
\hline Guo (27) & 2014 & Denmark & Colorectal & 400 & 253 & 21 \\
\hline $\operatorname{Lin}(28)$ & 2012 & China & Colorectal & 300 & 133 & 13 \\
\hline Cravioto-Villanueva (29) & 2012 & Mexico & Colorectal & 350 & 163 & 13 \\
\hline Sasaki (30) & 2012 & Japan & Colorectal & 370 & 636 & 77 \\
\hline
\end{tabular}

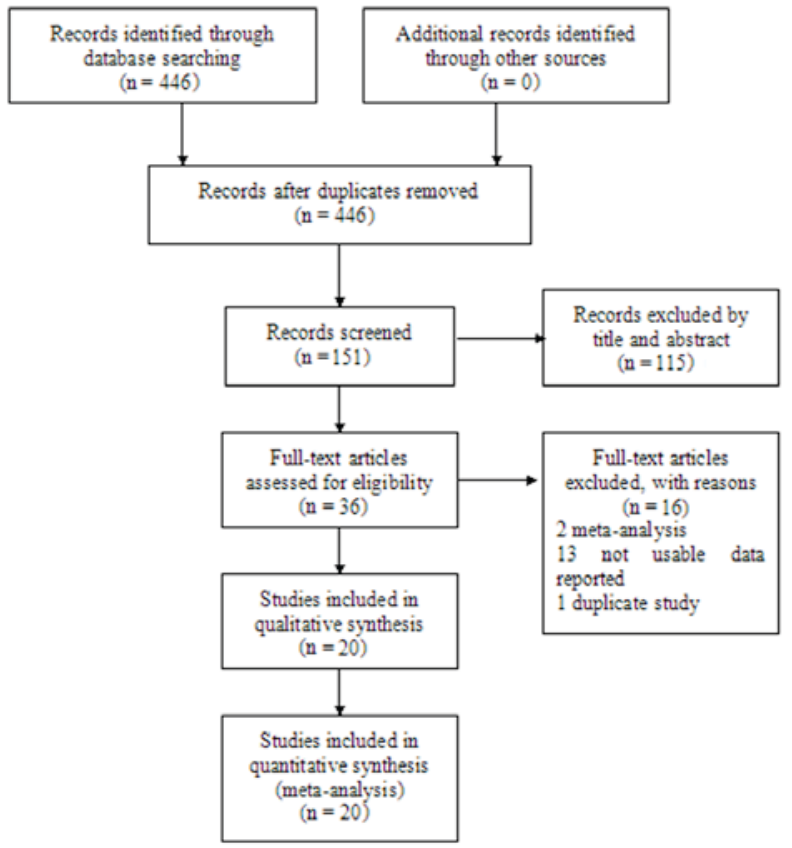

Figure 1. Flow diagram indicating the number of articles identified and selected using the criteria for inclusion and exclusion. A total of 20 studies were included in the present meta-analysis.

thrombocytosis and normal PLT count groups). The results revealed that none of these variables contributed a substantial proportion of the heterogeneity observed. Sensitivity analyses were performed following the sequential removal of each eligible study. Upon investigation of the thrombocytosis status and the 5-year overall survival rate of patients, the results suggested that the significance of the pooled ORs was not influenced by any individual study. 
Table II. Stratified analyses of the association between thrombocytosis and 5-year overall survival and TNM stage.

\begin{tabular}{|c|c|c|c|c|c|c|c|c|}
\hline \multirow[b]{2}{*}{ Variables } & \multicolumn{4}{|c|}{ 5-year overall survival } & \multicolumn{4}{|c|}{ TNM stage } \\
\hline & $\begin{array}{c}\text { Thrombocytosis } \\
\text { cases/total }\end{array}$ & OR $(95 \% \mathrm{CI})$ & P-value & $I^{2}(\%)$ & $\begin{array}{c}\text { Thrombocytosis } \\
\text { cases/total }\end{array}$ & OR (95\% CI) & P-value & $I^{2}(\%)$ \\
\hline \multicolumn{9}{|l|}{ Cancer types } \\
\hline $\begin{array}{l}\text { Gastrointestinal } \\
\text { cancer }\end{array}$ & $335 / 3853$ & $1.77(1.36-2.29)$ & 0.570 & 0 & $214 / 2180$ & $1.96(1.21-3.18)$ & 0.166 & 44.3 \\
\hline Lung cancer & $472 / 1956$ & $3.21(1.75-5.92)$ & 0.050 & 61.8 & $458 / 1753$ & $1.96(1.23-3.12)$ & 0.090 & 58.0 \\
\hline Renal cancer & $727 / 5403$ & $3.11(2.03-4.77)$ & 0.006 & 69.5 & $182 / 581$ & $3.16(1.20-8.32)$ & 0.070 & 69.5 \\
\hline \multicolumn{9}{|l|}{ Ethnicities } \\
\hline Asian & $519 / 5586$ & $3.06(1.76-5.34)$ & 0.001 & 76.5 & $239 / 2470$ & $2.64(1.42-4.90)$ & 0.017 & 70.6 \\
\hline African & $117 / 1792$ & $1.71(1.17-2.49)$ & 0.400 & 0 & - & - & - & - \\
\hline European & $898 / 3934$ & $2.72(1.91-3.90)$ & 0.040 & 54.7 & $615 / 2044$ & $1.89(1.38-2.59)$ & 0.229 & 30.6 \\
\hline
\end{tabular}

-, indicates that there were no studies investigating the association between thrombocytosis and advanced TNM stage in African patients. TNM, tumor-node-metastasis; OR, odds ratio; CI, confidence interval.

\begin{tabular}{|c|c|c|c|}
\hline \multicolumn{2}{|l|}{ Study ID } & \multicolumn{2}{|c|}{ OR $(95 \%$ CI $)$ Weight $\%$} \\
\hline \multicolumn{4}{|l|}{ Gastric cancer } \\
\hline $\operatorname{Li}(2014)^{[8]}$ & 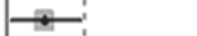 & $1.64(1.05-2.55)$ & 8.90 \\
\hline $\mathrm{Hu}(2014)^{[13]}$ & $\rightarrow$ & $1.84(0.93-3.65)$ & 6.91 \\
\hline Hwang $(2012)^{[14]}$ & $\rightarrow$ & $1.60(1.07-2.40)$ & 9.22 \\
\hline Wang (2012) $)^{[15]}$ & & $5.13(1.11-23.70)$ & ) 2.70 \\
\hline Guo (2014) [28] & & $2.68(1.00-7.15)$ & 4.89 \\
\hline Subtotal $\left(I^{2}=0.0 \%, P=0.572\right)$ & $<$ & $1.77(1.36-2.29)$ & 32.62 \\
\hline \multicolumn{4}{|l|}{ Lung cancer } \\
\hline $\operatorname{Kim}(2014)^{[16]}$ & & $2.63(0.90-7.64)$ & 4.43 \\
\hline Maráz (2013) $)^{[17]}$ & $\rightarrow$ & $1.92(1.17-3.14)$ & 8.45 \\
\hline Tomita $(2007)^{[18]}$ & & $4.39(1.33-14.44)$ & 3.86 \\
\hline Pedersen (1996) $)^{[19]}$ & 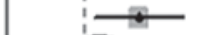 & $5.36(3.04-9.43)$ & 7.86 \\
\hline Subtotal $\left(l^{2}=61.8 \%, P=0.049\right)$ & & $3.21(1.75-5.92)$ & 24.59 \\
\hline \multicolumn{4}{|l|}{ Renal cancer } \\
\hline Brookman-May $(2013)^{[21]}$ & + & $4.79(3.70-6.19)$ & 10.33 \\
\hline Wosnitzer $(2010)^{[22]}$ & & $2.68(1.73-4.16)$ & 8.93 \\
\hline Suppiah (2006) ${ }^{[23]}$ & $\rightarrow$ & $2.29(1.11-4.73)$ & 6.59 \\
\hline Gogus (2004) [24] & 1 & $5.71(2.15-15.14)$ & 4.92 \\
\hline Inoue $(2004)^{[25]}$ & & $4.00(1.41-11.38)$ & 4.54 \\
\hline Symbas $(2000)^{[26]}$ & 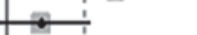 & $1.55(0.84-2.85)$ & 7.48 \\
\hline Subtotal $\left(l^{2}=69.5 \%, P=0.006\right)$ & & $3.11(2.03-4.77)$ & 42.79 \\
\hline Overall $\left(l^{2}=69.6 \%, P<0.001\right)$ & & $2.70(2.03-3.61)$ & 100.00 \\
\hline 1 & & & \\
\hline
\end{tabular}

Figure 2. Forest plot of the associations between thrombocytosis and the 5 -year overall survival of patients with cancer. OR, odds ratio; CI, confidence interval.

Publication bias. Begg's funnel plot and Egger's test were performed to assess publication bias. The funnel plots were not observed to indicate any marked asymmetry, which was subsequently supported by Egger's test revealing no statistical evidence of publication bias (Fig. 4).

\section{Discussion}

In the present study, thrombocytosis was defined as a PLT count of $>400 \times 10^{9} / 1$ in patients with malignancies. However, only one study focusing on colorectal cancer was in accordance with this standard; therefore, studies which defined thrombocytosis as PLT counts $>300 \times 10^{9}$ platelets $/ 1$ were included. It was established that single studies alone are of limited value in predicting cancer progression (31). Therefore, the present study performed a meta-analysis, including 1,739 patients with thrombocytosis and 11,039 patients with normal PLT counts from 20 published studies, in order to investigate the association between thrombocytosis and 5-year overall survival and tumor clinicopathological features.

The results of the present meta-analysis revealed that the 5 -year overall survival rate in the thrombocytosis group was significantly decreased, as compared with that of the normal PLT count group. Therefore, thrombocytosis may serve as a 


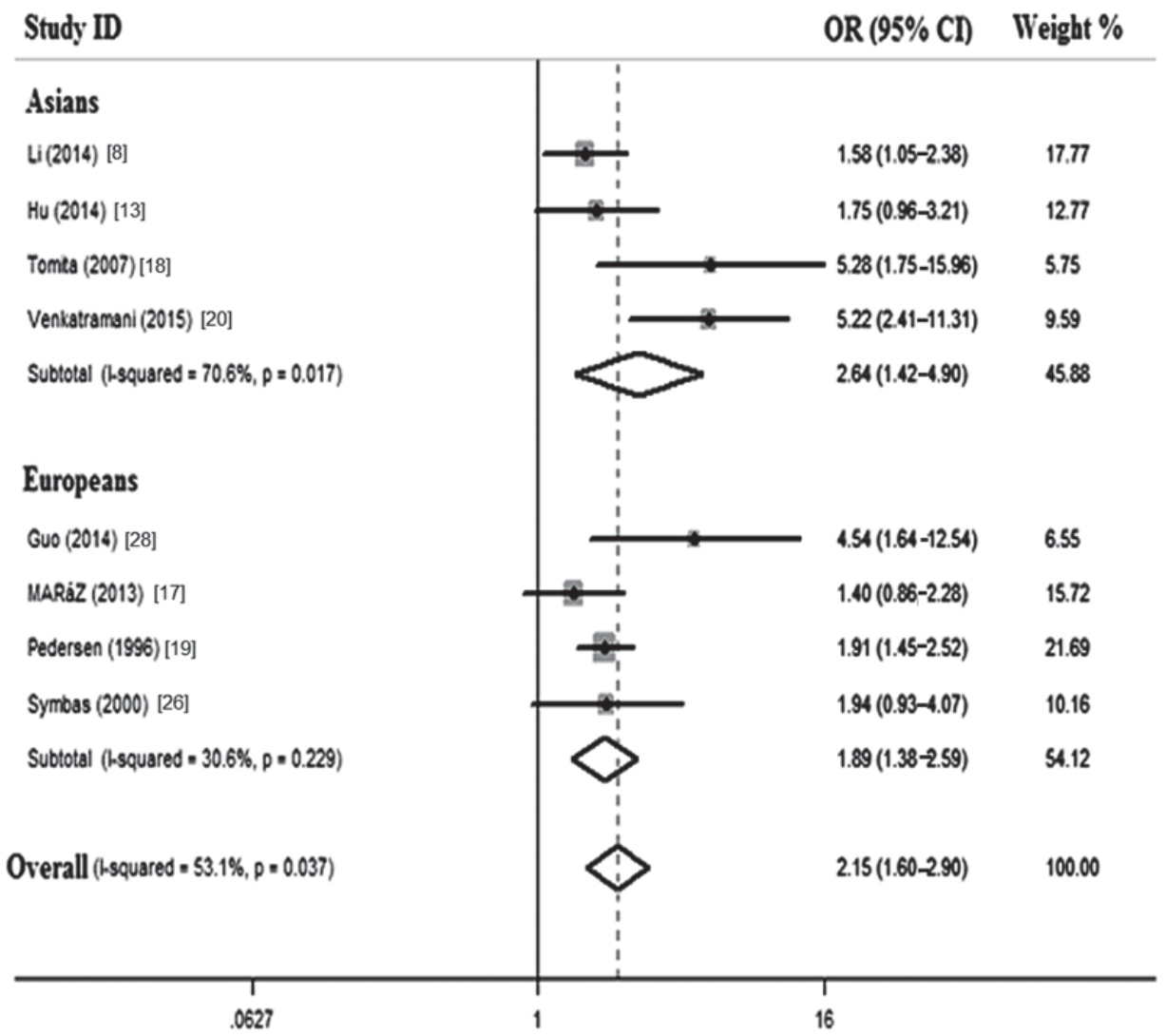

Figure 3. Forest plot of the associations between thrombocytosis and tumor-node metastasis stage of patients with cancer. OR, odds ratio; CI, confidence interval.

useful predictor of poor prognosis in patients with cancer. The present study also demonstrated that TNM stage, but not tumor differentiation, lymph node metastasis or tumor location, was an independent risk factor for thrombocytosis. In a subgroup analysis of the association between TNM and thrombocytosis, there were $\leq 3$ studies, with limited sample sizes, for each type of cancer; therefore, the results are to be interpreted with caution. These results indicated that thrombocytosis may be important in cancer development and progression, as numerous complex molecular mechanisms underlie cancer cell-PLT interactions (32). The potential predictive value of the association between thrombocytosis and 5-year overall survival and TNM stage revealed by the present study may be advantageous for use in clinical decision-making during risk categorization in patients with cancer. In previous meta-analyses by $\mathrm{Yu}$ et al (8) and Men et al (33), thrombocytosis was associated with a poorer prognosis for patients with gynecological malignancies and renal cancer. Concordantly, in the present subgroup analysis, thrombocytosis exhibited an increased association with poor prognosis for gastrointestinal, lung and renal cancer. The aforementioned meta-analysis $(8,33)$ did not investigate the association between thrombocytosis and clinicopathological

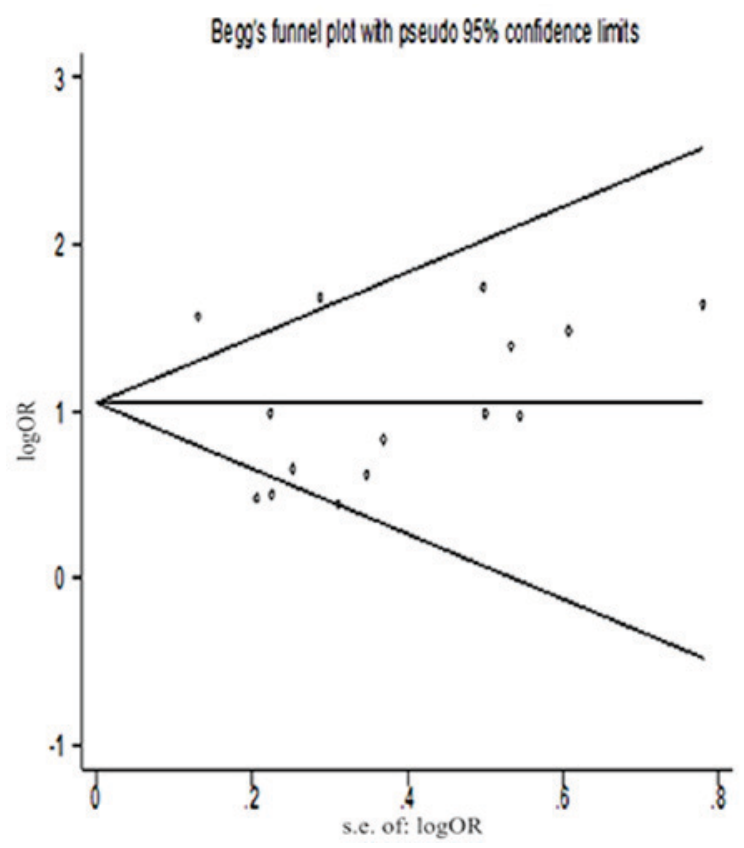

Figure 4. Funnel plots for the evaluation of potential publication bias in the impact of thrombocytosis on 5-year overall survival of patients with cancer. $\mathrm{SE}$, standard error; OR, odds ratio. 
features. Therefore, to the best of our knowledge, the current study is the first comprehensive meta-analysis to evaluate the association between clinicopathological features, 5-year overall survival and tumor-associated thrombocytosis in patients with cancer.

Previous studies have suggested that PLTs facilitate tumor cell survival, extravasation and angiogenesis; however, the mechanism underlying the thrombocytosis that develops in patients with malignant disease remains to be established $(34,35)$. A number of mechanisms underlying tumor-induced PLT activation and PLT-induced cancer progression have been reported $(36,37)$. Tumor-associated humoral factors, including interleukins 2 and 6, tumor growth factors (primarily vascular endothelial growth factor) and granulocyte colony-stimulating factor may have a role in promoting megakaryocyte growth and activating the coagulation cascade, resulting in activated PLT production (36). Tumor cell-induced PLT aggregation mediates the adhesion of PLTs to tumor cells and leukocytes, resulting in the formation of heteroaggregates, which enables the adhesion of cancer cells to the vascular endothelium and functions as physiological barrier, protecting tumor cells from the host immune system $(38,39)$.

The present study possessed certain limitations. The results of the meta-analysis were based on unadjusted estimates, and a more precise analysis is required in order to provide an adjusted estimate by age and gender, in cases where detailed individual data is available. The number of published studies was not sufficiently large, limiting the statistical power of the present study, particularly for any given cancer site. Despite these limitations, the current meta-analysis also had certain advantages. To the best of our knowledge, the present study is the first meta-analysis to assess the association between thrombocytosis and the prognosis and clinicopathological characteristics of patients with cancer. Additionally, the quality of studies included in the current meta-analysis was satisfactory and met the set inclusion criteria.

In conclusion, the results of the present meta-analysis suggested that thrombocytosis was associated with poor survival and advanced TNM stage, particularly for gastric cancer, as well as lung and renal cancer. Further studies with larger sample sizes and including additional types of cancer are required to investigate these findings.

\section{References}

1. Jemal A, Bray F, Center MM, Ferlay J, Ward E and Forman D: Global cancer statistics. CA Cancer J Clin 61: 69-90, 2011.

2. Wang S, Du H and Li G: Significant prognostic value of circulating tumor cells in esophageal cancer patients: A meta-analysis. Oncotarget: Feb 2, 2017 (Epub ahead of print).

3. Gakis G, Todenhöfer T and Stenzl A: The prognostic value of hematological and systemic inflammatory disorders in invasive bladder cancer. Curr Opin Urol 21: 428-433, 2011.

4. Stone RL, Nick AM, McNeish IA, Balkwill F, Han HD, Bottsford-Miller J, Rupairmoole R, Armaiz-Pena GN, Pecot CV, Coward J,et al: Paraneoplastic thrombocytosis in ovarian cancer. N Engl J Med 366: 610-618, 2012.

5. Kaloglu S, Guraslan H, Tekirdag AI, Dagdeviren H and Kaya C: Relation of preoperative thrombocytosis between tumor stage and grade in patients with endometrial cancer. Eurasian J Med 46: 164-168, 2014.

6. Borsig L: The role of platelet activation in tumor metastasis. Expert Rev Anticancer Ther 8: 1247-1255, 2008.
7. Li FX, Wei LJ, Zhang H, Li SX and Liu JT: Significance of thrombocytosis in clinicopathologic characteristics and prognosis of gastric cancer. Asian Pac J Cancer Prev 15: 6511-6517, 2014.

8. Yu M, Liu L, Zhang BL, Chen Q, Ma XL, Wu YK, Liang CS Niu ZM, Qin X and Niu T: Pretreatment thrombocytosis as a prognostic factor in women with gynecologic malignancies: a meta-analysis. Asian Pac J Cancer Prev 13: 6077-6081, 2012.

9. Sobin LH and Fleming ID: TNM classification of Malignant tumors, fifth edition (1997). Union internationale contre le cancer and the american joint committee on cancer. Cancer 80: 1803-1804, 1997.

10. Mantel N and Haenszel W: Statistical aspects of the analysis of data from retrospective studies of disease. J Natl Cancer Inst 22: 719-748, 1959.

11. Zoodsma M, Nolte IM, Te Meerman GJ, De Vries EG and Van der Zee AG: HLA genes and other candidate genes involved in susceptibility for (pre)neoplastic cervical disease. Int J Oncol, 26: 769-784, 2005.

12. Hu C, Chen R, Chen W, Pang W, Xue X, Zhu G and Shen X: Thrombocytosis is a significant indictor of hypercoagulability, prognosis and recurrence in gastric cancer. Exp Ther Med 8: 125-132, 2014

13. Hwang SG, Kim KM, Cheong JH, Kim HI, An JY, Hyung WJ and Noh SH: Impact of pretreatment thrombocytosis on blood-borne metastasis and prognosis of gastric cancer. Eur J Surg Oncol 38: 562-567, 2012.

14. Wang L, Huang X, Chen Y, Jin X, Li Q and Yi TN: Prognostic value of TP/PD-ECGF and thrombocytosis in gastric carcinoma. Eur J Surg Oncol 38: 568-573, 2012.

15. Kim M, Chang H, Yang HC, Kim YJ, Lee CT, Lee JH, Jheon S, Kim K, Chung JH and Lee JS: Preoperative thrombocytosis is a significant unfavorable prognostic factor for patients with resectable non-small cell lung cancer. World J Surg Oncol 12: 37, 2014.

16. Maráz A, Furák J, Varga Z, Kahán Z, Tiszlavicz L and Hideghéty $\mathrm{K}$ : Thrombocytosis has a negative prognostic value in lung cancer. Anticancer Res 33: 1725-1729, 2013.

17. Tomita M, Shimizu T, Hara M, Ayabe T and Onitsuka T: Prognostic impact of thrombocytosis in resectable non-small cell lung cancer. Interact Cardiovasc Thorac Surg 7: 613-615, 2008.

18. Pedersen LM and Milman N: Prognostic significance of thrombocytosis in patients with primary lung cancer. Eur Respir J 9: 1826-1830, 1996

19. Venkatramani V, Panda A and Kekre NS: Is thrombocytosis a useful prognostic marker in renal cell carcinoma? Results of a single-center retrospective analysis. Indian J Urol 31: 42-46, 2015.

20. Brookman-May S, May M, Ficarra V, Kainz MC, KampelKettner K, Kohlschreiber S, Wenzl V, Schneider M, Burger M, Wieland WF, et al: Does preoperative platelet count and thrombocytosis play a prognostic role in patients undergoing nephrectomy for renal cell carcinoma? Results of a comprehensive retrospective series. World J Urol 31: 1309-1316, 2013.

21. Wosnitzer M, Polland A, Hai Q, Hruby G and McKiernan J: Role of preoperative platelet level in clinical and pathological outcomes after surgery for renal cortical malignancies. BJU Int 108: 73-79, 2011.

22. Suppiah R, Shaheen PE, Elson P, Misbah SA, Wood L, Motzer RJ, Negrier S, Andresen SW and Bukowski RM: Thrombocytosis as a prognostic factor for survival in patients with metastatic renal cell carcinoma. Cancer 107: 1793-1800, 2006.

23. Göğüş C, Baltaci S, Filiz E, Elhan A and Bedük Y: Significance of thrombocytosis for determining prognosis in patients with localized renal cell carcinoma. Urology 63: 447-450, 2004.

24. Inoue K, Kohashikawa K, Suzuki S, Shimada M and Yoshida H: Prognostic significance of thrombocytosis in renal cell carcinoma patients. Int J Urol 11: 364-367, 2004.

25. Symbas NP, Townsend MF, El-Galley R, Keane TE, Graham SD and Petros JA: Poor prognosis associated with thrombocytosis in patients with renal cell carcinoma. BJU Int 86: 203-207, 2000.

26. Kim HJ, Choi GS, Park JS, Park S, Kawai K and Watanabe T: Clinical significance of thrombocytosis before preoperative chemoradiotherapy in rectal cancer: Predicting pathologic tumor response and oncologic outcome. Ann Surg Oncol 22: 513-519, 2015.

27. Guo T, Krzystanek M, Szallasi Z and Szallasi A: Thrombocytosis portends adverse prognostic significance in patients with stage II colorectal carcinoma. F1000Res 3: 180, 2014.

28. Lin MS, Huang JX, Zhu J and Shen HZ: Elevation of platelet count in patients with colorectal cancer predicts tendency to metastases and poor prognosis. Hepatogastroenterology 59: 1687-1690, 2012 . 
29. Cravioto-Villanueva A, Luna-Perez P, Gutierrez-de la Barrera M, Martinez-Gómez H, Maffuz A, Rojas-Garcia P, Perez-Alvarez C, Rodriguez-Ramirez S, Rodriguez-Antezana E and Ramirez-Ramirez L: Thrombocytosis as a predictor of distant recurrence in patients with rectal cancer. Arch Med Res 43: 305-311, 2012.

30. Sasaki K, Kawai K, Tsuno NH, Sunami E and Kitayama J: Impact of preoperative thrombocytosis on the survival of patients with primary colorectal cancer. World J Surg 36: 192-200, 2012.

31. Singh PB, Ragavan N, Ashton KM, Basu P, Nadeem SM, Nicholson CM, Krishna RK, Matanhelia SS and Martin FL: Quantified gene expression levels for phase I/II metabolizing enzyme and estrogen receptor levels in benign prostate from cohorts designated as high-risk (UK) versus low-risk (India) for adenocarcinoma at this organ site: A preliminary study. Asian J Androl 12: 203-214, 2010.

32. Choe KS, Correa D, Jani AB and Liauw SL: The use of anticoagulants improves biochemical control of localized prostate cancer treated with radiotherapy. Cancer 116: 1820-1826, 2010.

33. Men H, Liang $\mathrm{C}$ and $\mathrm{Yu}$ M: Thrombocytosis as a prognostic factor in patients with renal cell carcinoma: A meta-analysis of literature. J Cancer Res Ther 11: 67-72, 2015.

34. Verheul HM, Jorna AS, Hoekman K, Broxterman HJ, Gebbink MF and Pinedo HM: Vascular endothelial growth factor-stimulated endothelial cells promote adhesion and activation of platelets. Blood 96: 4216-4221, 2000.
35. Heng DY, Xie W, Regan MM, Warren MA, Golshayan AR, Sahi C, Eigl BJ, Ruether JD, Cheng T, North S, et al: Prognostic factors for overall survival in patients with metastatic renal cell carcinoma treated with vascular endothelial growth factor-targeted agents: Results from a large, multicenter study. J Clin Oncol 27: 5794-5799, 2009.

36. Kuenen BC, Levi M, Meijers JC, Kakkar AK, van Hinsbergh VW, Kostense PJ, Pinedo HM and Hoekman K: Analysis of coagulation cascade and endothelial cell activation during inhibition of vascular endothelial growth factor/vascular endothelial growth factor receptor pathway in cancer patients. Arterioscler Thromb Vasc Biol 22: 1500-1505, 2002.

37. Roselli M, Mineo TC, Basili S, Mariotti S, Martini F, Bellotti A, Ambrogi V, Spila A, D'Alessandro R, Gazzaniga PP, et al: Vascular endothelial growth factor (VEGF-A) plasma levels in non-small cell lung cancer: Relationship with coagulation and platelet activation markers. Thromb Haemost 89: 177-184, 2003.

38. Gay LJ and Felding-Habermann B: Contribution of platelets to tumour metastasis. Nat Rev Cancer 11: 123-134, 2011.

39. Mehta P: Potential role of platelets in the pathogenesis of tumor metastasis. Blood 63: 55-63, 1984. 